\title{
Н.Д. Титов
}

\section{НЕКОТОРЫЕ ОСОБЕННОСТИ ПРАВООТНОШЕНИЯ, ПОРОЖДАЕМОГО ДОГОВОРОМ ПОРУЧИТЕЛЬСТВА}

\begin{abstract}
Статья посвящена актуальным правовым проблемам последствий заключения и исполнения договора поручительства, обеспечивающего надлежащее исполнение основного обязательства, в том числе и будущего обязательства. Обосновьвается, что противоправность поведения поручителя не является условием возложения на него обязанности «отвечать» по обязательству поручительства. Поведение поручителя при нарушении обеспечиваемого обязательства должником и возложении на поручителя обязанности «отвечать» противоправным не является. Автором высказана идея, что законодатель лишь использует прием приравнивания гражданскоправовой ответственности к последствиям нарушения обеспечиваемого обязательства должником и исполнения обязательства поручителем.

Ключевые слова: правоотношение поручительства, акиессорность поручительства, исполнение обязательства поручителем.
\end{abstract}

Обязательство служит правовой формой реализации интересов и удовлетворения разнообразных потребностей его субъектов главным образом, но не исключительно имущественных. Общим местом в теории гражданского права считается утверждение, что гражданско-правовое обязательство не является абсолютно прочным правоотношением, безусловно гарантирующим его сторонам реализацию преследуемых ими договорных целей. В цивилистике аксиоматично утверждение о том, что любое обязательство подвержено риску его неисполнения либо ненадлежащего исполнения. Потребности и интересы, реализуемые сторонами при установлении обязательства и которые являются его внутренней движущей силой, внутренними стимулами к исполнению добровольно установленного обязательства, не всегда обеспечивают (гарантируют) достижение правовых и экономических целей.

В связи с этим в законе предусмотрены дополнительные, внешние по отношению к субъектам обязательства, правовые способы, повышающие надежность исполнения, стимулирующие к исполнению обязательства и достижению его целей, компенсирующие потери сторон при нарушении основного (обеспечиваемого) и обеспечительного обязательства (ст. 329 ГК РФ). В их числе в ст. 329 ГК РФ указано поручительство.

Поручительство широко применяется на практике, и в целом его можно оценить, вопреки бытующему мнению, не абсолютно, но как достаточно надежный способ обеспечения исполнения обязательств. С практической стороны степень его надежности во многом зависит от самих сторон поручительского правоотношения, их предусмотрительности, понимания правового и экономического механизмов обеспечительного действия поручительства, слабых мест института поручительства, возможности использовать данную правовую форму в ущерб должнику. Но субъекты гражданского оборота должны понимать главное - поручительство лишь снижает риск отрицатель- 
ных имущественных последствий нарушения обеспечиваемого обязательства, может лишь минимизировать возникшие отрицательные имущественные последствия в случае нарушения основного (обеспечиваемого) обязательства, но не устраняет его вовсе. Понимание данной особенности поручительства должно побуждать кредитора в основном обязательстве к принятию мер, дополняющих обеспечительное действие поручительства, восполняющих недостаточную надежность поручительства, усиливать гарантирующий потенциал исполнения основного обязательства.

Поручительство обеспечивает, прежде всего, надлежащее исполнение основного (денежного) обязательства, выполняя до нарушения обеспечиваемого обязательства стимулирующую функцию (в отношении должника в основном обязательстве) посредством угрозы взыскания исполненного кредитору должника убытков и процентов. В случае нарушения должником обеспечиваемого (основного) обязательства и исполнения поручителем лежащей на нем обязанности поручительство выполняет компенсационную функцию и с ослабленным действием - стимулирующую функцию.

Компенсационная функция поручительства реализуется с помощью специфического правового механизма: поручитель, исполнивший свое договорное обязательство, занимает место кредитора в другом (основном, обеспечиваемом) обязательстве. Цель такого закрепленного в законе механизма заключается в обеспечении права поручителя взыскать с должника исполненное им по обязательству поручительства, возместить убытки, понесенные в связи с исполнением обязанности за должника, и взыскать проценты на сумму, выплаченную кредитору, т.е., другими словами, защитить права поручителя (п. 1 ст. 365 ГК РФ).

Основанием для обращения с требованием к поручителю является правонарушение, допущенное должником в обеспечиваемом обязательстве. Оценка основания обращения с требованием кредитора к поручителю не может и не должна сводиться, как представляется, только к договору поручительства. Особенность взаимосвязи основного (обеспечиваемого) и договора поручительства дает основание для вывода о том, что необходимо учитывать и другой юридический факт - правонарушение, допущенное должником в основном обязательстве. Таким образом, основанием обязанности поручителя возместить отрицательные имущественные последствия, которые наступили у кредитора в связи с совершенным должником правонарушением и объем которых предусмотрен в договоре поручительства, является юридический состав, включающий: договор поручительства и нарушение обязательства, исполнение которого обеспечивается поручительством. Однако для замены кредитора в обеспечиваемом обязательстве на поручителя (нового кредитора) необходим дополнительный юридический факт - исполнение поручителем лежащей на нем обязанности, предусмотренной договором поручительства, по требованию кредитора.

Поручительством может быть обеспечено как существующее к моменту заключения договора поручительства обязательство, так и будущее обязательство (ст. 361 ГК РФ). По обоснованному мнению С.В. Сарбаша, будущее обязательство необходимо идентифицировать для устранения неопределенности в отношении обеспечиваемого обязательства, «ибо ответственность 
поручителя не может быть предположительной» [1. С. 38]. Действительно, не может быть договора поручительства, стороны которого указали в качестве обеспечиваемого «обязательство, которое возникнет в будущем». Надлежащая степень идентификации будущего обязательства может осуществляться различными способами, в частности, путем определения условий будущего договора в самом договоре поручительства, путем заключения предварительного договора, определяющего условия будущего договора и порождаемого им обязательства, заключения самостоятельного договора, определяющего все необходимые параметры будущего обязательства.

Идентификация - это определение основных параметров будущего обязательства, требуемых законом, иными правовыми актами, определяемых соглашением. Но сами по себе параметры обязательство не образуют и не порождают. Для того чтобы «будущее обязательство» преобразовалось в обязательство, которое обеспечивает договор поручительства, необходим соответствующий юридический факт, который соответствует согласованным сторонами договора параметрам обеспечиваемого обязательства.

Обладает ли договор поручительства, обеспечивающий будущее обязательство, свойством акцессорности? ${ }^{1}$ Ответ на данный вопрос во многом зависит от понимания сущности акцессорности. По нашему мнению, акцессорность - это свойство определенных гражданско-правовых обязательств, которое раскрывается через содержательные признаки: производность, дополнительность и зависимость обязательств. Основные признаки обеспечительных (акцессорных) обязательств закреплены в пп. 2, 3 ст. 361 ГК РФ. Договор поручительства, обеспечивающий исполнение будущего, надлежащим образом идентифицированного обязательства, является акцессорным, ему присущи признаки производности, дополнительности и зависимости от обеспечиваемого обязательства.

Свойством акцессорности обладают не только обеспечительные обязательства. Однако следует отметить, что акцессорность как свойство определенных гражданско-правовых обязательств не стала предметом специальных научных исследований. В литературе акцессорность иногда трактуется упрощенно, лишь как взаимосвязь возникновения и существования основного и обеспечительного обязательства (ст. 329 ГК РФ), что не отражает, на наш взгляд, всей сложности, глубины и богатства взаимосвязи и взаимозависимости обеспечиваемого и обеспечительного обязательств (подробное обоснование данной позиции выходит за пределы темы данной статьи).

Не только научный интерес, но и практическое значение представляет вопрос о сущности правоотношения, возникающего из договора поручительства, до нарушения будущего обязательства. Скорее всего, данный вопрос является частью более общей проблемы правовой природы правоотношения, порождаемого договором поручительства. Не рассматривая его в полном

\footnotetext{
${ }^{1}$ По мнению Р.С. Бевзенко, практически все имеющиеся в распоряжении кредитора, использующего российское обязательственное право, обеспечительные конструкции основаны на принципе акцессорности, предполагающем невозможность существования обеспечительного права без обеспеченного договором долга. См.: Бевзенко Р.С. Новеллы судебной практики в сфере поручительства. Комментарий к постановлению Пленума ВАС РФ от 12.07.2012 № 42 «О некоторых вопросах разрешения споров, связанных с поручительством» // Вестник ВАС РФ. 2012. № 11. С. 47.
} 
объеме, укажем, что в п. 2 постановления Пленума ВАС РФ от 12.07.2012 № 42 «О некоторых вопросах разрешения споров, связанных с поручительством» разъяснено, что договор поручительства будущего обязательства «считается заключенным сторонами, а предусмотренные им дополнительные права и обязанности... возникшими с момента достижения сторонами такого договора в установленной форме согласия по его существенным условиям» [2. С. 47]. Вместе с тем редакция данного пункта представляется недостаточно четкой, возможно его различное толкование и понимание. Однако в принципиальном плане с приведенной позицией ВАС РФ о моменте заключения договора поручительства и его последствиях с момента заключения следует согласиться. Противоположный вывод не соответствовал бы прямому указанию ст. 361 ГК РФ. По смыслу данной нормы закона и из ее буквального прочтения следует, что договор поручительства заключается для обеспечения обязательства, которое возникнет в будущем.

Возникает вопрос: порождает ли договор поручительства до достижения согласия относительно существенных условий будущего договора какиелибо права и обязанности, может ли он содержать условия, порождающие права и обязанности сторон договора поручительства с момента его заключения, влечет ли он какие-либо правовые последствия? Думается, что на него должен быть дан утвердительный ответ. По смыслу ст. 361 ГК РФ и из буквального прочтения ее следует, что для обеспечения исполнения будущего обязательства договор поручительства должен быть заключен. Как следует из указанного постановления Пленума ВАС РФ, дополнительные права и обязанности возникают с момента достижения сторонами такого договора в установленной форме согласия по его существенным условиям. Согласие по существенным условиям должно быть достигнуто по обеспечиваемому обязательству. Дополнительно к каким правам и обязанностям? Представляется, что к тем, которые порождены договором поручительства до достижения соглашения по всем существенным условиям. Видимо, Пленум ВАС РФ исходит из того, что с момента заключения договор поручительства порождает определенные права и обязанности. Дополнительные права и обязанности возникают с момента достижения соглашения по обеспечиваемому обязательству.

По существу Пленум ВАС РФ высказался по более общей и дискуссионной проблеме, а именно: порождает ли договор поручительства регулятивное обязательство или до нарушения основного обязательства договор поручительства никаких прав и обязанностей не порождает. Данная проблема широко обсуждается в юридической литературе $\mathrm{e}^{1,2}$, высказаны различные точки зрения [3. С. 91; 4. С. 733-739; 5. С. 17-39].

\footnotetext{
${ }^{1}$ Подробный анализ высказанных точек зрения по данной проблеме см.: Бакин А.С. Понятие субсидиарного обязательства в гражданском праве РФ // Вестн. Том. гос. ун-та. 2010. № 339.; Он же. О проблеме единства критерия классификации субсидиарной ответственности по законодательству Российской Федерации // Вестн. Том. гос. ун-та. 2014. № 380.

${ }^{2}$ Глубокий анализ условному обязательству дан в работе: Васнев В.В. Природа условного обязательства до разрешения отлагательного условия // Вестн. ВАС РФ. 2012. №12. С. 23-58. Казалось бы, это две различные проблемы: правовая природа правоотношения, возникающего из договора поручительства, и условного обязательства. Однако авторы, занимающиеся их исследованием, сталкиваются с близкими или аналогичными проблемами.
} 
По нашему мнению, более обоснованной представляется позиция тех авторов, которые считают, что договор поручительства с момента заключения порождает регулятивное правоотношение, обладающее значительным своеобразием, а с момента нарушения основного (обеспечиваемого) обязательства возникает охранительное обязательство поручительства, в рамках которого реализуется ранее возникшее право кредитора требовать исполнения и исполняются обязанности должника (поручителя).

В соответствии со ст. 361 ГК РФ по договору поручительства поручитель обязывается перед кредитором другого лица отвечать за исполнение последним его обязательства полностью или в части. Из легального определения следует, что договор поручительства - это соглашение, направленное на установление правоотношения (ст. 361 ГК РФ). Распространенным в доктрине является мнение о том, что договор поручительства без промежуточного регулятивного правоотношения сразу порождает охранительное обязательственное правоотношение. Конечно, нельзя отрицать, что договор поручительства и порождаемое им правоотношение обладают значительным своеобразием. Однако это не исключает того, что с момента заключения договор поручительства порождает регулятивное правоотношение, содержание которого составляют права и обязанности, реализуемые (осуществляемые) в рамках охранительного правоотношения.

Нельзя признать удовлетворительными и различные представления, существующие в литературе, об основании, порождающем обязанность поручителя «отвечать» за исполнение должником обязательства. Как правило, исследователи указывают в таком качестве договор поручительства. Вряд ли с этим можно согласиться. Сторонники такой точки зрения оставляют без внимания иные юридические факты, имеющие важное значение для возникновения обязанности поручителя «отвечать» и перехода к нему права требовать возмещения понесенных им имущественных потерь от должника в основном (обеспечиваемом) обязательстве. Основанием обязанности поручителя «отвечать» является юридический состав: нарушение должником основного обязательства (правонарушение), договор поручительства и требование, предъявленное поручителю об исполнении поручительского обязательства.

Одной из особенностей охранительного поручительского правоотношения является то, что его возникновение не связано с противоправным поведением поручителя (должника) в договоре поручительства. Противоправным является поведение должника в основном (обеспечиваемом) обязательстве, совершившего правонарушение, но в котором поручитель участия не принимает и реальной возможностью влиять на его исполнение не обладает. Как бы ни трактовать понятие противоправности (широко, узко, своеобразно), поведение поручителя при нарушении основного обязательства должником противоправным не является. Противоправным может быть поведение лишь того субъекта, который нарушает нормативный запрет, правовые императивные предписания, условия сделки, судебные решения, устанавливающие запреты, предписания или обязанности, требования (обязанности), устанавливаемые иным юридическим фактом. Обязанность поручителя основана на его добровольно выраженном согласии «отвечать». Эта особенность оказывает влияние на основания (набор юридических фактов) и условия возникновения ука- 
занной обязанности. Не может быть квалифицировано поведение поручителя противоправным и потому, что он добровольно принял на себя обязанность «отвечать». Такой противоправности поведения субъекта гражданского права цивилистика не знает.

Авторы, занимающиеся проблемой обеспечения исполнения обязательств поручительством, не могут предложить более или менее убедительную аргументацию высказываемых мнений о сущности последствий исполнения обязательства поручителем при нарушении должником обеспечиваемого обязательства. Трудности в квалификации указанных последствий связаны с самим законом. На наш взгляд, законодатель лишь использует прием приравнивания гражданско-правовой ответственности к последствиям нарушения обеспечиваемого обязательства должником и исполнения обязательства поручителем ${ }^{1}$. Причины использования данного приема заключаются в отсутствии убедительного теоретического обоснования правовой природы последствий нарушения обязательства должником для лица, которое в нем (в обеспечиваемом обязательстве) участия не принимает, влиять на его исполнение возможности не имеет.

\section{Лuтература}

1. Сарбаш С.В. Некоторые проблемы обеспечения исполнения обязательств // Вестн. ВАС РФ. 2007. № 7.

2. Вестник ВАС РФ. 2012. № 9.

3. Гонгало Б.М. Учение об обеспечении обязательств. Вопросы теории и практики. М.: Статут, 2004. $221 \mathrm{c.}$

4. Гражданское право: актуальные проблемы теории и практики / под общ. ред. В.А. Белова. М.: Юрайт-Издат, 2007. 993 с.

5. Белов В.А. Поручительство. Опыт теоретической конструкции и обобщения арбитражной практики. М., 1998. 236 с.

Titov Nikolay D. Tomsk State University (Tomsk, Russian Federation)

\section{SOME PECULIARITIES OF LEGAL RELATIONSHIP ARISING OUT OF A SURETY CONTRACT.}

Keywords: legal relationship of surety, accessority of surety, performance of an obligation by a guarantor.

The obligation existing on the moment of the conclusion of a surety contract and any future obligation (in case of its proper identification) can be secured by surety. A surety contract securing any future obligation has the feature of accessority, because it derives from the given obligation, complements it and depends on it.

One of the features of a securing surety legal relationship is that its emergence is not connected with wrongdoing of a guarantor (a debtor in a surety contract). Wrongdoing is a violation of a secured obligation by a debtor but a guarantor does not take part in it and cannot influence the performance of this obligation so his behavior is not a wrongdoing. But a person is a wrongdoer if he/she violates normative injunctions, legal imperative prescriptions, conditions of a transaction, court decisions which impose injunctions, prescriptions or obligations, claims (obligations) ascertained by another legal fact. The obligation of a guarantor is his voluntarily expressed agreement "to be responsible". This feature influences the grounds (set of legal facts) and emergence conditions of the above obligation. A guarantor's behavior cannot be characterized as an unlawful one due to the fact that he volun-

${ }^{1}$ Глубокий и интересный анализ использования данного приема законодателем в частном праве дан в работе: Ровный В.B. Прием приравнивания в частном праве (понятие и особенности реализации). Иркутск: Изд-во Иркут. гос. ун-та, 2014. С. 7. 
tarily agreed "to be responsible". Civil law does not know anything about such wrongdoing on the part of the subject of civil law. All difficulties in the qualification of the above consequences are connected with the law itself. The author of the article thinks that legislators try to equate civil legal liability with the consequences of violation of a secured obligation by a debtor and performance of an obligation by a guarantor.

Such equating can be explained by the lack of a profound theoretical substantiation of the legal nature of the consequences of violation of an obligation by a debtor for the person who in not involved in a secured obligation and, thus, cannot influence its performance.

\section{References}

1. Sarbash S.V. Nekotorye problemy obespecheniya ispolneniya obyazatel'stv [Some problems to enforce the obligations]. Vestnik VAS RF, 2007, no. 7.

2. Vestnik VAS RF, 2012, no. 9.

3. Gongalo B.M. Uchenie ob obespechenii obyazatel'stv. Voprosy teorii i praktiki [The doctrine of the secured obligation. The theory and practice]. Moscow: Statut Publ., 2004. 221 p.

4. Belov V.A. (ed.) Grazhdanskoe pravo: aktual'nye problemy teorii i praktiki [The civil law: the current theory and practice]. Moscow: Yurayt-Izdat Publ., 2007. 993 p.

5. Belov V.A. Poruchitel'stvo. Opyt teoreticheskoy konstruktsii i obobshcheniya arbitrazhnoy praktiki [The guaranty. The experience in the theoretical design and synthesis of arbitrary practice]. Moscow: YurInfoR Publ., 1998. 236 p. 